\title{
Electric Versus Gas Lighting for Motorcycles"
}

\author{
Gain in Illumination, Reliability, Light Weight, and Other Factors
}

\section{By L. C. Porter}

Tire popularity of electric lighting that has made such rapid strides on automobiles has extended to the inotorcycle fleld. These small but speedy machines require a powerful headlight; one which is reliable and safe. Ease in manipulating the lighting unit is as much desired by the motorcyclist as by the more fully equipped autoist. It is estimated that there are now in use, in this country, some 500,000 motorcycles, an this year's preduction will probably increase this flgure by 125,000 . Many of these machines are frequently used during the evening, and most of them are at present equipped with gas lights of one form or another

GENERAL ADVANTAGE

Owing to a wide difference of opinion among rider no definite rule for the requirements of the motorcyclist can be made, but many miles of riding over all kind of roads and under various weather conditions has convinced the writer that he has a gøod understandin of the general requirements of a motorcyclist

Motorcycles are driven as fast as, frequently faster than aut•mobiles, which fact alone demands a powerful headlight for safe operation. It is necessary for the motorcyclist to see the røad as clearly, and nearly as far ahead as the driver of an automobile. It is no necessary, however, for him to see sø great a width o road; a headlight covering 6 to 10 feet is ample.

A machine equipped with electric lights carries with it numerous advantages which tend toward increasing

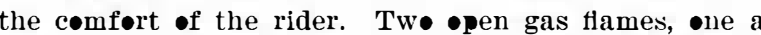
few feet ahead and the other a few feet back of two and one-half gallons of gasoline, are not very safe and one-half gallons of gasoline, are not very safe, especially in case of accident. With electrie lighting, - the simple turn of a switch. There is no gas tank key to lose; there are n॰ damp matches to wrestle with or shield from the wind. Any rider who has been unfortunate enough to get a puncture on a country road at night will never forget the difficulty experienced in locating and patching the hole by what little light was thrown back of the gas headlight. With electric lighting it is a simple matter to rig up a trouble lamp which can be easily and safely moved around to any desired spot.

Electric lights also permit the use of a small speed -meter lam, electric horn, and other useful accessorie - great conveniences-making night riding as satisfactory as day. With compressed gas, there is always a possibility of the tank running empty in places where it is difficult to reflll it. On the other hand, there is hardly a country village where dry batteries canne

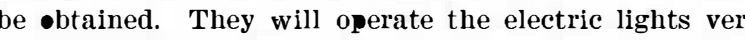
satisfactorily for many hours, until a place is reached where it is convenient to recharge the storage battery. The intensity of electric headlights remains practically constant, while to obtain the same result with ga it is necessary to keep continually opening the gas cock as the pressure decreases.

The weight of the lighting equipment is also to be considered. The lighter the machines, the less the wear - n tires, etc. Figures are given later in this discussion which show that the electric equipment is lighter. No electric motorcycle lights were found on the market, but several automøbile types can be easily adapted to motorcycle use. Small gas tail lamps can be easily converted into electric by replacing the gas burner with an electric lamp.

The question of current supply is one which for som time delayed the electric lighting of motorcycles. There are, however, several makes of unspillable storage batteries now on the market for this purpose. These ar of tw॰ types, 4 and 6 volt. The 4 -volt batteries are more compact and lighter than the 6 -volt, but it is the writer's opinion that the use of a 6 -volt battery is well worth the extra space and weight. It enables the use -f 6-volt lamps, which can be purchased at almost any sarage or electric supply house, while many of these
llaces do not carry 4-volt lamps. One concern has an electric generator for motorcycles on the market; an -ther is working on a combination low tension magnete and storage battery for this purpose. Storage batteries of approximately 10 ampere-hour capacity, 4 or 6-volt (preferably 6) are ample for a week's service, riding every evening, provided a little care is used and the light turned off when not in actual service. This is comparable with the service of a compressed gas tank, operating a $1 / 2$ cubic foot headlight burner and a $1 / 8$ cubic foot tail light.

* Reproduced from the General Electric Review.

\section{ROAD TESTS.}

Three electric lamps of varying fllament concentration but of equal candle-power were placed on the motorcycle, one at a time, and used for headlights at low and high speed, over rough and smooth roads. It was found that the lamp with extreme concentration gave too narrow a beam for satisfactory riding; the bent-back-loop filament, or one of little concentration, gave a beam which covered a great deal more of the road than was necessary; while the screw type, or auto headlight filament, came the nearest to meeting the requirements. It was determined that frøm 6 t॰ 10

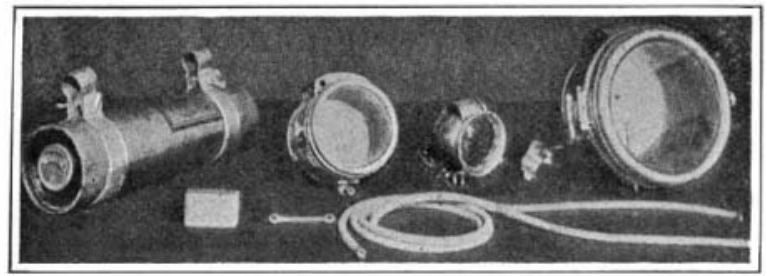

Fig. 1.-A 4-inch and a 6-inch gas motorcycle headlight, and the necessary gas apparatus to operat either.

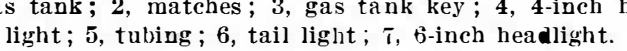

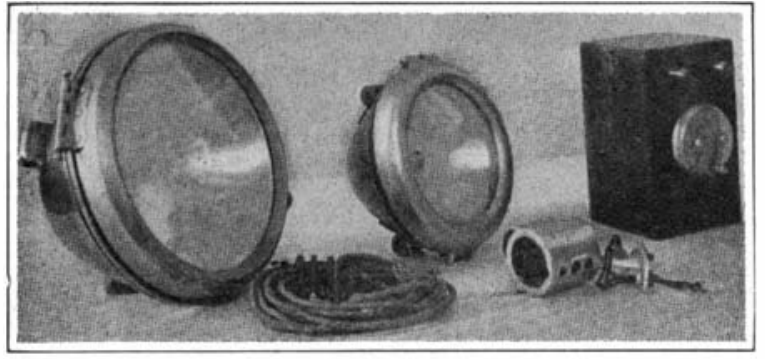

Fig. 2.-A $4 \frac{1}{2}$-inch and 7 -inch electric headlight, and the necessary equipment to operate either. , wire; $3,4 \frac{1}{2}-1$ ight $; 5$, battery.
ling

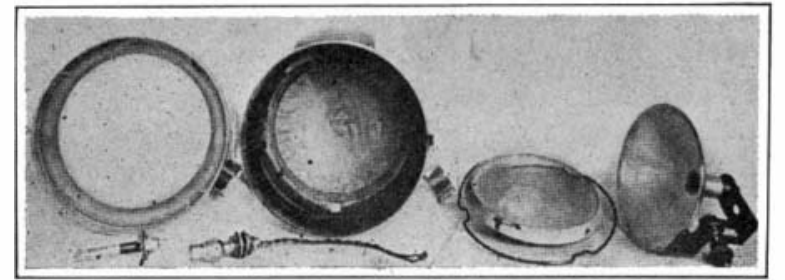

Fig. 3.-Gas lamp ready for converting to electric -with electrical apparatus.

1, gas burner; 2 , electric socket; 3, 6-inch lamp casing; 4,
mangin mirror and retaining wire; 5, parabolic reflector mangin mirro

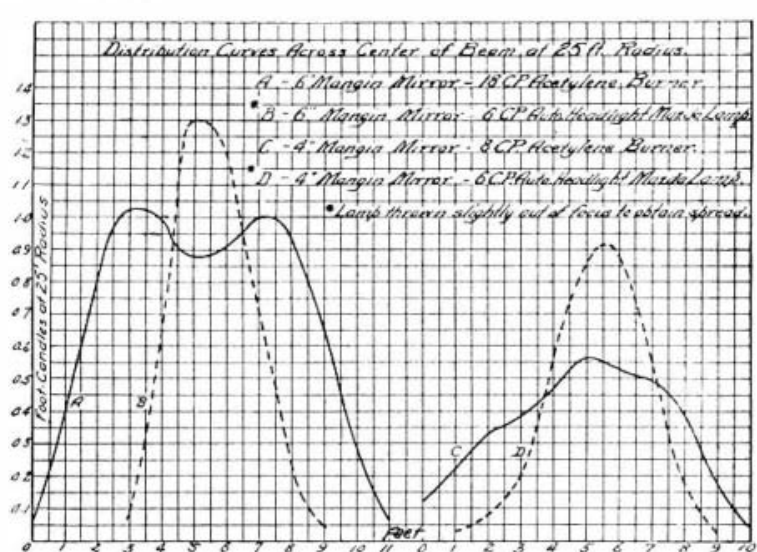

Fig. 4.-Curves showing the difference of intensity and distribution across the center of beam, at feet radius, thrown by two sizes of gas and electric headlights, using mirror reflectors.

feet $\bullet$ the røad should be lighted for satisfact $\bullet$ ry work The writer alsø found that for the best results the center of the beam should be directed on the road 25 feet ahead of the machine.

Having determined the type of fllament which gave the most satisfactory results, the next step was to determine the size of lamp necessary. In order to make a thorough study of the subject, various oil, gas and electric equipments were purchased and tried out on an Indian motorcycle under severe conditions. It was found that oil lamps were out of the question for motorcycle use. Even when mounted on the fork of the front wheel they did not give sufficient illumination for even slow riding. A well known gas lamp, consisting of a combination lamp and generator, was also tried. It was found that while the light given was sufficient for slow riding, at any speed above 10 miles an hour the beam was not powerful enough to enable the rider to discover obstacles on the road in time to avoid them. Riding on rough roads or striking a bump on an ordinary road would jar down such an excess of water into the carbide that a rush of gas would be generated so great as to make the flame roar, lose its luminosity, and endanger the mirror.

The only satisfactory gas equipment was found to be a headlight •perated from compressed gas. With this equipment twe sizes of headlights were used, one cønsisting of a 4-inch Mangin mirror back of a $1 / 4$ cubic foot burner, and the other a 6-inch Mangin mirror back of a $1 / 2$ culic foot burner. These headlights, with the necessary equipment to operate either, are shown in Fig. 1. It was found that the 4-inch headlight was satisfactory for general urban use, but when it came to high speed work on country roads, the light was hardly powerful enough to be satisfactory. The 6 -inch headlight gave an excellent light; however, the flame was sø far from a pøint source that the light spread not only over the road, but over the ditches as well. If the same volume of light could be concentrated into a beam covering but 6 or 10 feet of the road and of greater intensity, a much more satisfactory light would result. This is exactly what is accomplishe by the electric headlight.

In these tests both parabolic reflectors and Mangin mirrors were used. Lamps of $2,4,6,8,10$, and 10 candle-power were tried. It was found that for slow riding, 2 candle-power lamps furnished sufficient light. l'or rough roads or high speed work, the $S$ candle-power lamps were found to be amply powerful. For general use, the best lamp was found to be 6 candle-power.

There are many gas headlights in use on motorcycles to-day. In order to determine the possibility of converting these into satisfactory electric lamps, the gas burners in tw• gas lamps (•ne equipped with a 4-inch and the other with a 6-inch Mangin mirror) were replaced by lamp sockets. The 6 candle-power screw type fllament lamp was used in each case. It was found that with this lamp located at the focus of the reflector, a very powerful but very narrow beam was -btained-one which was to narrow for safe riding. When the lamp was located between the focal point and the mirrør, a gøod spread was obtained, but there was a dark spot in the center of the beam. When, høwever, the lamp was located a short distance ahead of the focus, a very satisfactory beam was obtained. With both the 4-inch and the 6-inch headlights, beams were obtained which were decidedly better than the gas beams. They were more powerful, and while not having sø great a spread, were sufficient for comfortable riding, at the same time being very steady. The 4-inch headlight was found to be sufficiently powerful for ordinary use, but as with the gas, the 6-inch light was rerguired for high speed or rough roads.

$A$ search was made for an electric headlight for a

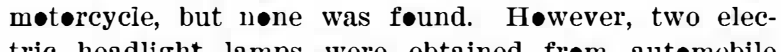
tric headlight lamps were obtained from automobile alparatus. One consisted of a 7-inch parabølic reflector and casing, used as a small auto headlight; the -ther of a $51 / 1$-inch reflector (only $41 / 2$-inch being effective, due to the door covering the edge of the reflector) used for an aute sidelight. Both of these headlights are illustrated in Fig. 2. The 7-inch reflector equipped with the 6 candle-power lamp mentioned above made a most excellent headlight. It was much more powerful than the 6-inch gas lamp and had ample spread; in fact, this lamp was more powerful than necessary. Equiped with a 2 candle-power lamp, it gave very good light, as did alse the converted side lamp.

One prominent manufacturer makes a 6 -inch parabolic reflector complete with bracket and lamp socket for converting gas to electric light. This is illustrated in Fig. 3, together with the other parts involved in tha conversion. $\because$ Gas headlights having a 6-inch or larger mirr $\bullet$ can be converted to excellent electric headlights by remøving the gas burner and mirror, and replacing them with this reflector. This can be done in a few minutes with a pair of pliers. The gas burner is removed from the casing by simply unscrewing the base unit. The mirror is removed by pulling out the piece of stiff spring brass wire shown in Fig. 3. The rellector and bracket can then be inserted and held in a simj- 
lar manner to the old gas burner. If the rider does not care to purchase the reflector outfit, however, the gas burner can be replaced by an electric socket, •btainable at almost any auto supply house. Such a socket is shown in front of the lamp easing in Fig. 3.

$$
\text { LABORATORY TESTS. }
$$

In order to obtain some comparative figures on gas and electric lighting for motorcycles, photometer tests were conducted on both. The gas lamps used were equipped with a 6 -inch Mangin mirror and $1 / 2$ cubic foot burner and a 4 -inch Mangin mirror and $1 / 1 / 2$ cubic foot burner. Acetylene gas was supplied to these lamps from a compressed gas tank. The flame was turned up as high as it would go without roaring.

The candle-power of the two gas burners alone was measured and then distribution curves were taken An exastion of the data and corves $A$ and $C$, shows that the burner is 18 , while that of the $1 / 1$ cubic foot burner is 8 . The distribution across the beam at 25 feet shows wide spread with maximum intensities of 1.08 and 0.56 footcandles. The curves show that the beams are a little uneven. After these, curves were taken from the headlights with the gas burners replaced by the 6 candlepower tungsten lamp. The lamp was thrown sufficiently far ahead of the focal point to give good spread. These curves, $B$ and $D$, Fig. 4 , show that the beam thus obtained is even, and while the spread is not so great as the gas, the beam covers a sufficient amount of the road for safe riding and has a higher intensity than the gas in the center, $i$. e., directly in front of the motorcycle reaching 1.3 and 0.92 foot-candles.

In order to determine the intensity of light that would be thrown on a stone, the side of a hole, or other obstruction in the road at various distances ahead of the machine, photometer readings were taken on a plane 38 inches below the headlight (the height of the light above the ground when mounted on motorcycle handlebars) with the center of the beam directed on the ground 25 feet ahead of the light. These readings, curves $A$ and $C$, Fig. 5, show the normal illumination on an obstruction in the road, from 5 to 50 feet directly in front of the machine.

Next, similar tests were conducted on the two sizes of electric headlights, each being a parabolic reflector quipped with a 6 candle-power tungsten lamp, on having an effective surface 7 inches in diameter, and the other $4 \frac{1}{2}$ inches. Curves $A$ and $B$, Fig. 6 , show that the 7-inch lamp has a spread (6 to 10 feet) sufficiently great for satisfactory riding and throws a beam of nearly five times the intensity of the 6 -inch gas or

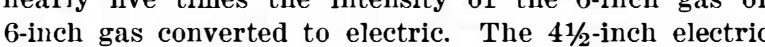
lamp also has geod spread, and is more powerful than the small gas or gas converted lamp.

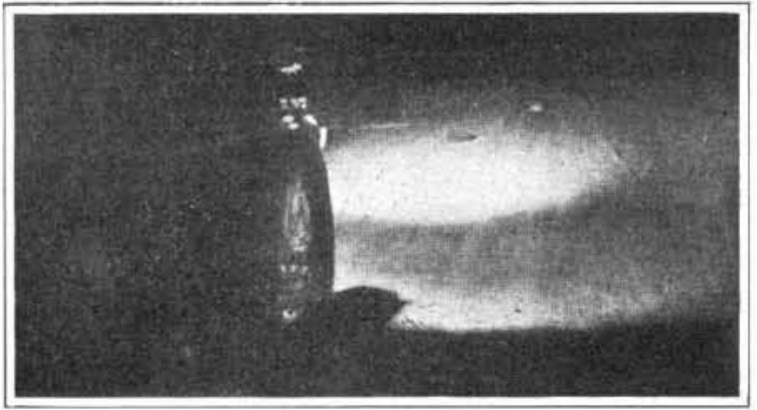

Fig. 7.-Illumination given by a 6-inch gas headlight, showing stones a distance of 25 and 50 feet ahead.
Photographs which were taken of the road illumination given by various gas and electric equipments, are shown in Figs. 7,8 and 9 .

The weights of the various apparatus were found to be as follows

6-inch gas headlight and brackets...... $4 \mathrm{lb} . \quad 13 \frac{1}{2} \mathrm{oz}$. 4-inch gas heudlight and brackets.

Tail lamp and brackets

2 lb. 7 oz.

$11 \frac{1}{2} \mathrm{oz}$.

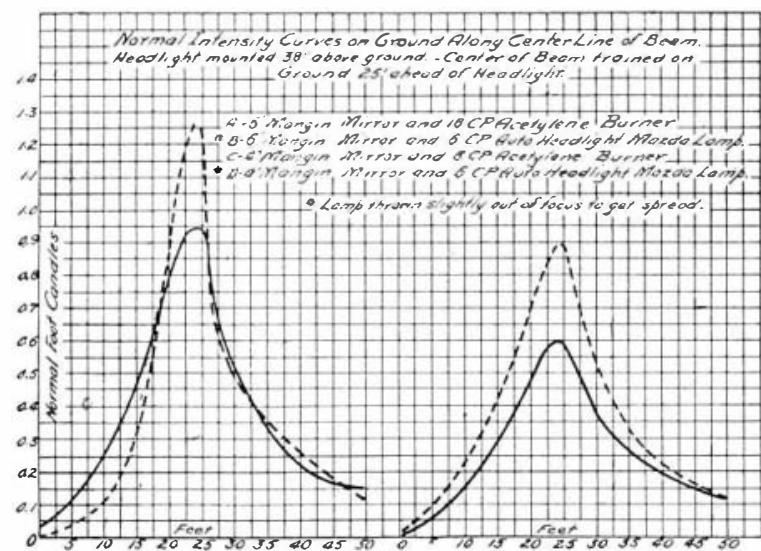

Fig. 5.-Curves of normal intensity on ground along center line of beam from two sizes of gas and electric headlights using mirror reflectors.

tric headlights using mirror reflectors.
$A$, full line curvc; $B$, dotted curve; $C$, full line curve; $D$

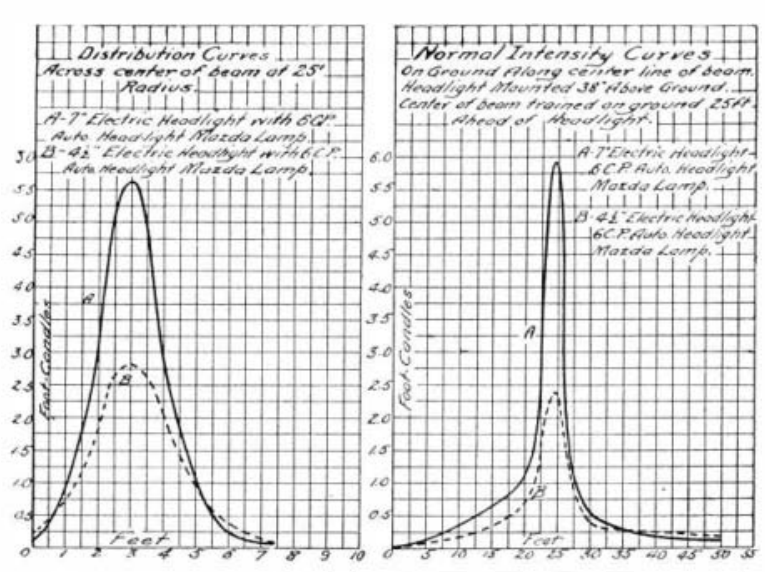

Distribution curves across center of
beam at $25 \mathrm{ft}$. radius

Fig. 6.-Curves showing characteristics of beam projected from a 7 -inch and a $4 \frac{1}{2}$-inch electric headlight, employing parabolic reflectors.

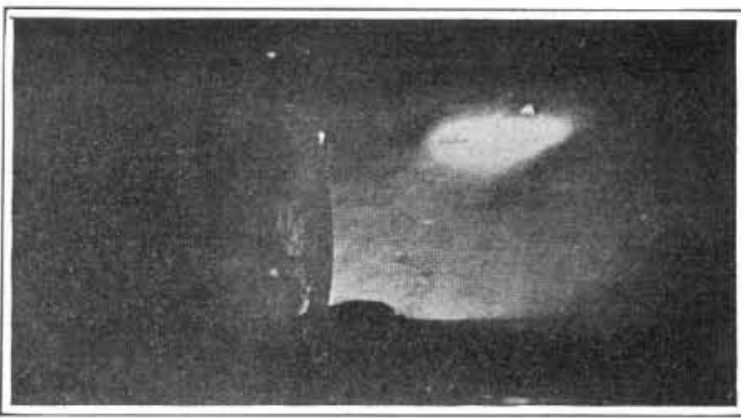

Fig. 8.-Illumination given by a 6-inch gas head light converted to electric, showing stones 25,50 and 100 feet ahead.

\section{Rubber tubing}

Gas tank key

Total with 6-inch lamp.

$3 / 4$ oz

$15 \mathrm{lb} .12 \frac{1}{4} \mathrm{oz}$

1:3 11). ij oz.

7-inch headlight and brackets. ...

$4 \mathrm{lb} . \quad 6 \quad 0 \mathrm{z}$

$41 / 2$-inch headlight and brackets....... $3 \mathrm{lb}, 10 \quad 0 z$

Tail lamp and brackets.............. $\bar{j}$ oz

6-volt, 10 ampere-hour battery........ $111 \frac{1}{2} \mathrm{lb}$.

4-volt, 10 ampere-hour battery....... $7 \mathrm{ll}$. 9 oz.

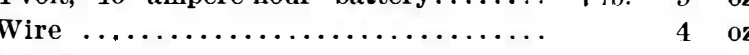

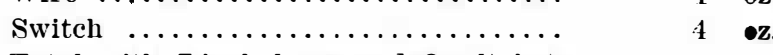

Total with 7 -inch lamp and 6 -volt bat-

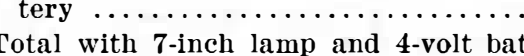

tery $\ldots \ldots \ldots \ldots \ldots \ldots \ldots \ldots \ldots \ldots \ldots \ldots \ldots \ldots$.

tery $\ldots \ldots \ldots \ldots \ldots \ldots \ldots \ldots \ldots \ldots \ldots \ldots \ldots \ldots, 15 \mathrm{lb}, 12 \quad 0$. Total with $41 \frac{1}{2}$-inch lamp and 4 -volt bat-

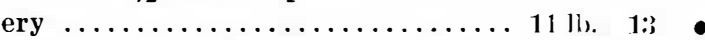

The space occupied by the various equipments was also measured, and found to be considerillyy less for the electric outfit, the storage battery occupwing about one half the space required by the gas tank. The headlight $\bullet$ ccupied nearly the same space; the electric tail light considerably less.

CONCLUSIONS.

As a result of the tests, the writer draws the following conclusions: Electric lighting is very satisfactory; it enables the user to obtain a powerful headlight, giving a steady beam, no matter how rough the road; the beam does not fall in intensity, as does that of a gas lamp, which requires continual opening of the valve; no matches are required, and there is no gas tank key to lose; the lamp can be easily focused to give a long, pøwerful beam for country use, or a wide spread at lower intensity in the city. Flectric lighting can be controlled by the simple turning of a switch; it enables the use of a small tail lamp, a speedometer lamp, and a trouble lamp, the latter being of great service; it enables the use of a small electric horn; the storage battery can, if necessary on a long trip, be temporarily replaced by dry batteries, which are obtainable anywhere.

The operation of electric lighting is very much more convenient than that of gas. The space occupied is less, meaning a neater equipment. Very satisfactory electric outfits can be obtained with little trouble, and but slight expense where gas is now in use, by simply replacing the gas headlight burner with a 6 candlepower electric lamp and socket, the gas tail light burner with a $1 / 2$ candle-power tungsten, and the gas tank by a small storage battery. Where new outfits are purchased even more powerful headlight lamps can be obtained.

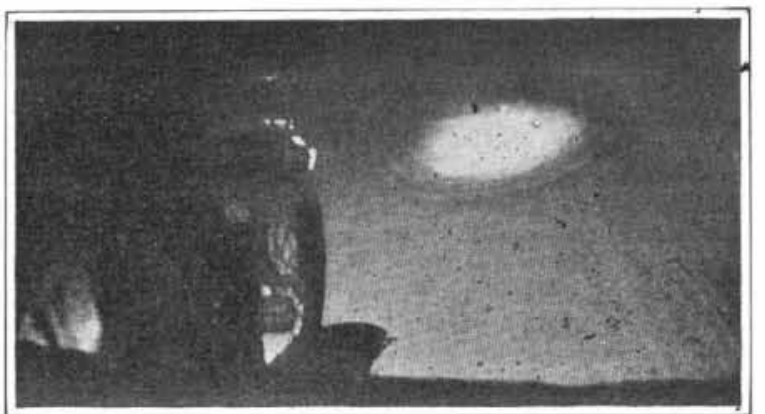

Fig. 9.-Illumination given by a 7-inch electric headlight, showing stones 25, 50, 100 and 200 feet ahead.

\section{Artificial Daylight for Color Matching}

\section{The Requisite Components of Light Sorted Out by Means of Light Filters}

By Robert French Pierce

Wherever discrimination between or matching of colors is necessary, deceiving and sometimes almost unbelievable errors are apt to be introduced by the light in which the colors are viewed. No only do all the artificial lights, no matter how white they may appear to the eye, distort colors from their so-called "daylight" values, but the north-sky itself, the most uniform of natural light sources, is notoriously unreliable.

A match made under a cloudless north-sky may, with some delicate colors, prove far from a match under a cloudy sky. Furthermore, the modifications of north-skylight introduced by reflection from green foliage, red brick buildings, etc., of ten prove so deceptive that a match made in one portion of a plant may not be duplicated in another. understood, because most plainly in evidence in the dyeing of textiles in which delicate and complex dyes are used, but lithographers, engravers, printers, color grinders, paper makers, etc., often find that even with the less sensitive mineral pigments, the sky is by no means a dependable light source for color matching.

No less frequently is the purchaser of dress goods, printed matter, stains, paints, etc., disappointed over the results of matching samples under artificial light, or under daylight distorted by reflections from surrounding buildings, etc.

While it is true that not all fabrics or colored objects are to be worn or displayed under daylight or even under approximately white light, it is obvious that matching may be best done under the partioular kind of light originally used by the dyer or color maker. Subsequent estimates of the appearance of the fabric or object under any artificial light may be made under the particular light required, but this operation is far more deceptive than is usually supposed. For instance, it might be thought that material for a ball-gown might well be matched under electric incandescent light, but if the match be made under tungsten lamps in a store, and the gown be worn in a ball-room lighted by small low efficiency carbon filament lamps, such as are often used for decorative or artistic lighting effects, the result is apt to be anything but pleasing.

Since manufacturer, retailer and user of fabrics and materials in which color is an important feature have long suffered from the lack of an artificial light duplicating daylight and at the $\operatorname{same} \operatorname{tim} \theta$ 